\title{
Two new species of the genus Anufrievia Dworakowska from China (Hemiptera: Cicadellidae: Typhlocybinae)
}

\author{
Weiwen Tan $\ddagger$, Jia Jiang ${ }^{\ddagger}$, Yuehua Song ${ }^{\ddagger}$ \\ ‡ School of Karst Science, Guizhou Normal University / State Key Laboratory Cultivation Base for Guizhou Karst Mountain \\ Ecology Environment of China, Guiyang, 550001, China
}

\author{
Corresponding author: Yuehua Song (songyuehua@163.com) \\ Academic editor: Colin Favret \\ Received: 29 Apr 2021 | Accepted: 26 May 2021 | Published: 03 Jun 2021 \\ Citation: Tan W, Jiang J, Song Y (2021) Two new species of the genus Anufrievia Dworakowska from China \\ (Hemiptera: Cicadellidae: Typhlocybinae). Biodiversity Data Journal 9: e68043. \\ https://doi.org/10.3897/BDJ.9.e68043
}

ZooBank: urn:Isid:zoobank.org:pub:5A078994-03EC-4701-9CAE-931EE8FB0889

\section{Abstract \\ Background}

The leafhopper genus Anufrievia Dworakowska, 1970 includes 33 species and is widely distributed in China, Korea, South Korea, Japan, Nepal, India, Thailand and Vietnam.

\section{New information}

Two new species found at Bijie City and Shibing County, Guizhou Province, China are described and illustrated, $A$. crispata sp. nov. and $A$. confluensa sp. nov. A key to distinguish the Chinese species of the genus is given.

\section{Keywords}

Homoptera, Auchenorrhyncha, Erythroneurini, taxonomy, leafhopper 


\section{Introduction}

The leafhopper genus Anufrievia Dworakowska, 1970 belongs to the tribe Erythroneurini of Typhlocybinae, with Anufrievia rolikae Dworakowska, 1970 as its type species (Dworakowska 1970). The genus previously contained 33 species, including 28 species in China (Cao et al. 2018). In this paper, two new species from Guizhou Province, China are described and illustrated and a key to distinguish the Chinese species of the genus is provided.

The characteristics of Anufrievia genus are as follows. Body yellow or white, often with brown markings or diffuse patterns. Head slightly narrower than pronotum. Length of crown distinctly shorter than inter ocular width. Body length $2.0-4.0 \mathrm{~mm}$ (including wing). Vertex anterior margin with minute paired black spots. Male anteclypeus narrow and flat, greyish, brown or black. Pronotum pale, scutellum with dark lateral triangles. Forewing with $4^{\text {th }}$ apical cell small, not reaching apex of forewing, $2^{\text {nd }}$ apical cell nearly rectangular and $1^{\text {st }}$ apical cell broad. Hind wing venation follows typical schemes for Erythroneurini taxa. Abdominal apodemes small and narrow, extended dorsomesad.

Male pygofer lobe with hind margin sleeked or truncated slightly, basal lateral angle usually with macrosetae, sometimes absent and scattered a few fine setae in outer lateral surface. Pygofer dorsal appendage articulated to pygofer lobe with ventral appendage absent. Subgenital plate with some macrosetae in mid-ventral part, broad basally and sometimes terminal half tapering abruptly; row of stout setae along upper margin from sub-base to apex. Apex of style pointed, bifid, foot-shaped or otherwise modified. Aedeagus with dorsal apodeme well developed; aedeagal shaft tubular; gonopore sub-basal to subapical on ventral surface. Connective lateral arms long, Y- or V-shaped.

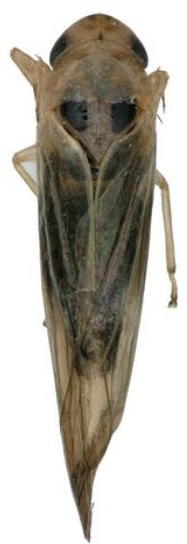

A

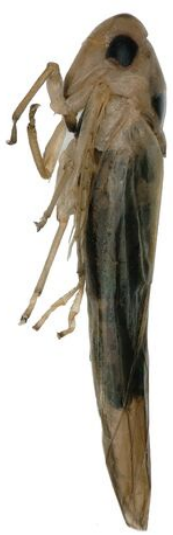

B

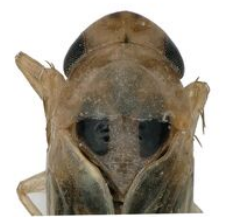

C

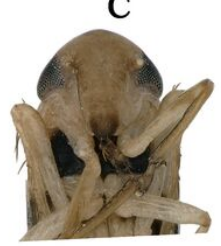

D

Figure 1. doi

Anufrievia crispata sp. nov. A. Habitus, dorsal view; B. Habitus, lateral view; C. Head and thorax, dorsal view; D. Face. 


\section{Materials and methods}

All specimens in this study were collected by the sweeping-net method. Morphological terminology used follows Dietrich (2005) and Dworakowska (1993). An Olympus SZX16 dissecting microscope was used for observing and an Olympus BX53 stereomicroscope for drawing. A KEYENCE VHX-5000 digital microscope was used for taking habitus photos. Body measurements are from the apex of the vertex to the tip of the forewing. All specimens examined were deposited in the collection of the School of Karst Science, Guizhou Normal University, China (GZNU).

\section{Taxon treatments}

\section{Anufrievia crispata, sp. $\mathrm{n}$.}

\section{- ZooBank 6C5F6BDB-CDAB-4407-857F-72CF40893FF7}

\section{Materials}

Holotype:

a. $\quad$ scientificName: Anufrievia crispata; order: Hemiptera; family: Cicadellidae; genus: Anufrievia; specificEpithet: crispata; country: China; stateProvince: Guizhou; locality: Bijie City, Qixinguan District, Salaxi Town; locationRemarks: label transliteration: "Guizhou, Bijie, 24. 10. 2019, coll. Zhouwei Yuan and Xiao Yang"; individualCount: 1; sex: male; lifeStage: adult; collectionCode: Insects; basisOfRecord: PreservedSpecimen

\section{Paratype:}

a. scientificName: Anufrievia crispata; order: Hemiptera; family: Cicadellidae; genus: Anufrievia; specificEpithet: crispata; country: China; stateProvince: Guizhou; locality: Bijie City, Qixinguan District, Salaxi Town; locationRemarks: label transliteration: "Guizhou, Bijie, 24.10. 2019, coll. Zhouwei Yuan and Xiao Yang"; individualCount: 4; sex: male; lifeStage: adult; collectionCode: Insects; basisOfRecord: PreservedSpecimen

\section{Description}

Body brownish-black. Head brownish-yellow, with pair of small dark brown apical spots (Fig. 1A and C). Eyes black. Face brownish-yellow, frontoclypeus brownish and anteclypeus centrally brown with black lateral margins (Fig. 1B and D). Pronotum light brownish (Fig. $1 \mathrm{~A}$ and $\mathrm{C}$ ). Scutellum brownish-yellow, with black basal triangles (Fig. $1 \mathrm{~A}$ and $\mathrm{C}$ ). Forewing beige (Fig. $1 \mathrm{~A}$ and $\mathrm{B}$ ). Abdominal apodemes broad, extended to 4 th sternite (Fig. 2A). Male length 3.7-4.0 mm (including wing).

\section{Diagnosis}

Male genitalia. Pygofer lobe with numerous microsetae distributed densely along dorsal and near posterior margin, few fine setae scattered on lateral surface (Fig. 2B). Pygofer dorsal appendage broadened at base, tapering towards apex (Fig. 2C). Subgenital plate robust, with three macrosetae near mid-length on lateral surface, 
several peg-like setae distributed from sub-base to apex; several microsetae scattered on apical portion (Fig. 2D). Style with two points apically; pre-apical lobe prominent (Fig. 2E). Aedeagal shaft curved dorsally, with serrated marginal lamellae on shaft; pair of small processes curved mesally gonopore; subapical on ventral surface (Fig. $2 \mathrm{~F}$ and G). Connective V-shaped, slender (Fig. 2H).

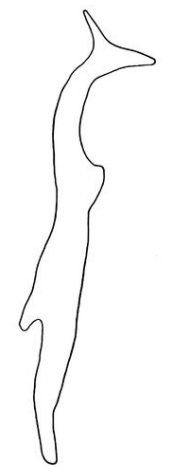

E

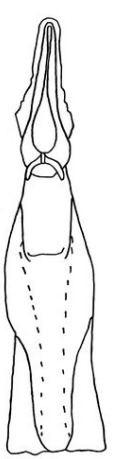

$\mathbf{F}$

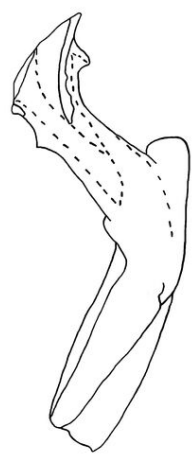

G

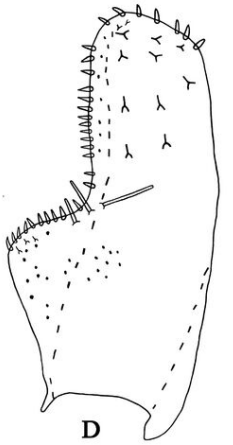

D

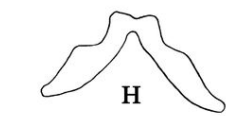

$\mathrm{H}$

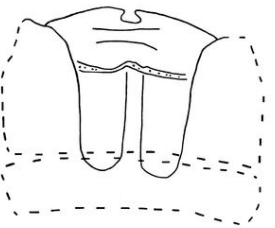

A

Figure 2. doi

Anufrievia crispata sp. nov. A. Abdominal apodemes; B. Pygofer lobe; C. Pygofer dorsal appendage, lateral view; D. Subgenital plate; E. Style F. Aedeagus, ventral view; G. Aedeagus, ventrolateral view; H. Connective.

\section{Etymology}

The new species is named from the Latin word "crispatus", referring to the serrated marginal lamellae on both sides of shaft apex dorsad (Fig. $2 F$ and $G$ ).

\section{Taxon discussion}

This species can be distinguished from other species in this genus by the unique characters of the aedeagus: the aedeagal shaft with serrated marginal lamellae on both sides of apex, pair of small curved processes subapically; short dorsal apodeme and long prearium. 


\section{Anufrievia confluensa, sp. $\mathrm{n}$.}

\section{- ZooBank 67AE0DA0-127A-4D2B-9B54-FD0CD9EC78C4}

\section{Material}

Holotype:

a. scientificName: Anufrievia confluensa; genus: Anufrievia; specificEpithet: confluensa; country: China; stateProvince: Guizhou; county: Shibing; locationRemarks: label transliteration: "Guizhou, Shibing, 24.7.2019, coll. Zhouwei Yuan and Xiao Yang"; individualCount: 1; sex: male; lifeStage: adult; collectionCode: Insects; basisOfRecord: PreservedSpecimen

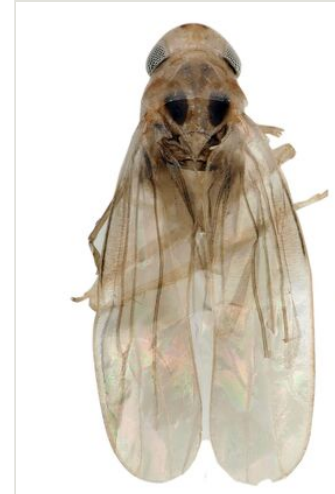

A

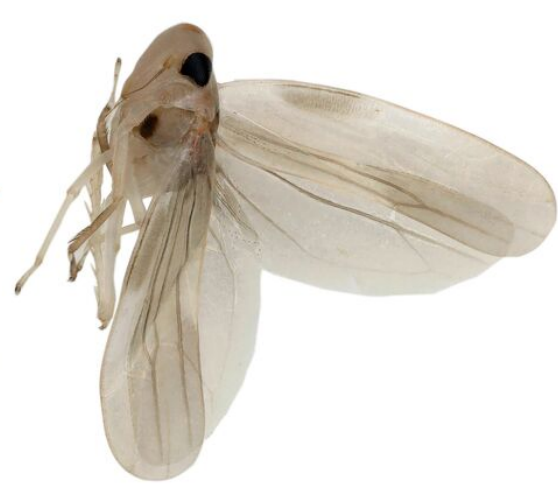

B

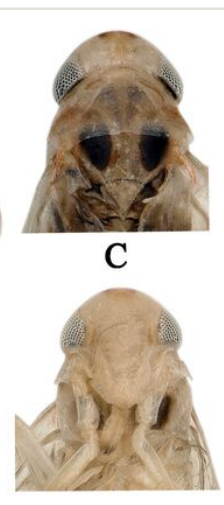

D

Figure 3. doi

Anufrievia confluensa sp. nov. A. Habitus, dorsal view; B. Habitus, lateral view; C. Head and thorax, dorsal view; D. Face.

\section{Description}

Male length $2.8 \mathrm{~mm}$ (including wing). Body yellowish. Vertex brownish-yellow, with pair of small dark brown apical spots (Fig. 3A and C). Eyes grey. Face pale milky yellow, anteclypeus and frontoclypeus light brownish (Fig. 3B and D). Pronotum and scutellum brownish-yellow and anterior margin of scutellum with black triangles (Fig. 3A and $C$ ). Forewing beige (Fig. 3A and B). Abdominal apodemes very short, not extended to $3^{\text {rd }}$ sternite (Fig. 4A).

\section{Diagnosis}

Male genitalia. Pygofer lobe broad, with dense microsetae near dorso-caudal margin and several peg-like setae on outer surface (Fig. 4B). Pygofer dorsal appendage broadened at base, tapering towards apex (Fig. 4C). Subgenital plate slightly concave near middle area, with three macrosetae on lateral margin, row of short stout setae along upper margin from sub-base to apex (Fig. 4D). Style with two points at apex; pre- 
apical lobe small (Fig. 4E). Aedeagal shaft straight and flat in lateral view, but long and slim in ventral view; gonopore arising from ventral surface, reaching two thirds of aedeagal shaft; dorsal apodeme well developed (Fig. 4F and G). Connective Y-shaped, two arms slender, central lobe absent (Fig. 4H).

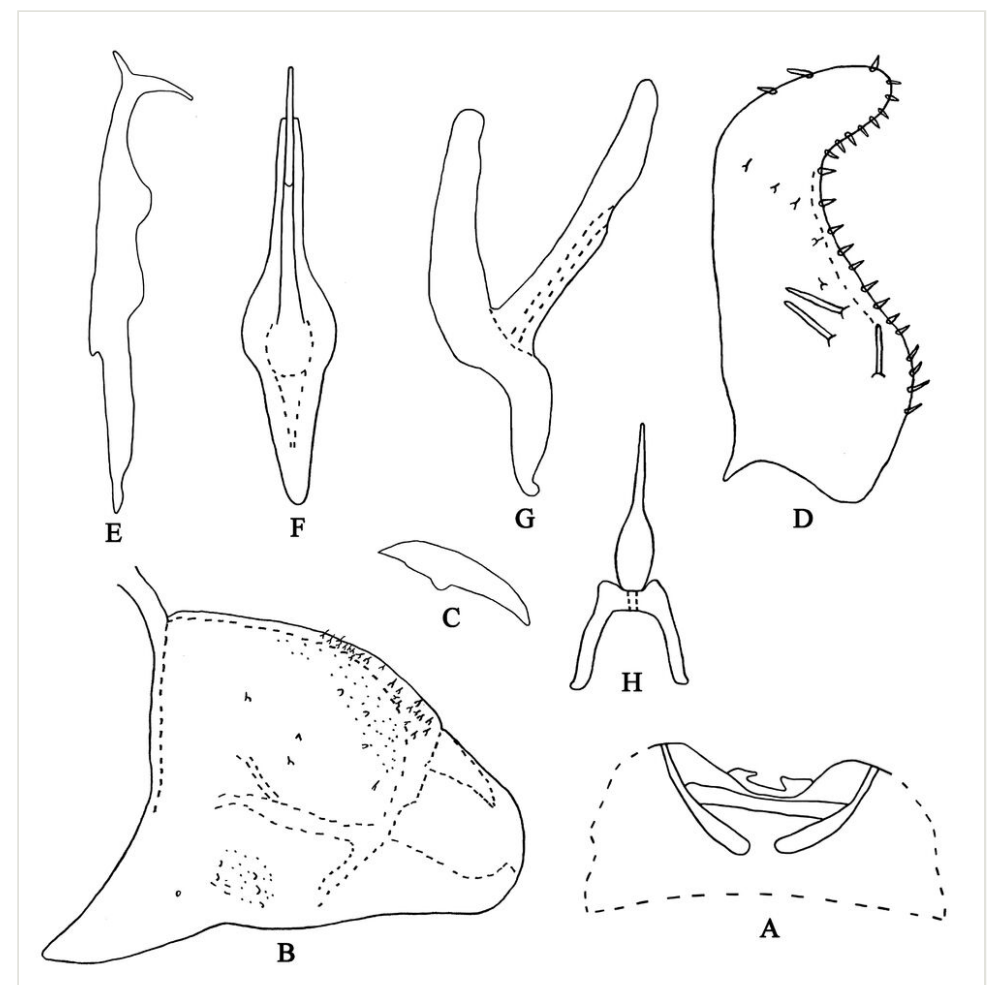

Figure 4. doi

Anufrievia confluensa sp. nov. A. Abdominal apodemes; B. Pygofer lobe; C. Pygofer dorsal appendage, lateral view; D. Subgenital plate; E. Style; F. Aedeagus, ventral view; G. Aedeagus, lateral view; H. Connective.

\section{Etymology}

The new species is named from the Latin word "confluensus", referring to the connective stem fused with a long process (Fig. $4 \mathrm{H}$ ).

\section{Taxon discussion}

This species is similar to $A$. akazu (Matsumura 1932), but can be recognised by the subapical ventral surface without paired short processes and pygofer appendage not bifurcate at apex. 


\section{Identification keys}

\section{Key to males of Anufrievia from China (modified from Cao et al. 2018)}

\begin{tabular}{|l|l|l|}
\hline 1 & Pygofer dorsal appendage not bifurcate at apex & 2 \\
\hline- & Pygofer dorsal appendage bifurcate at apex & 11 \\
\hline 2 & Aedeagus with large dorsal apodeme & A \\
\hline- & Aedeagus with small dorsal apodeme & 4 \\
\hline 3 & Pre-atrial process not reaching gonopore & 8 \\
\hline- & Pre-atrial process reaching or surpassing gonopore & 5 \\
\hline 4 & Style without distinct apical and subapical teeth & 6 \\
\hline- & Style with distinct apical and subapical teeth \\
\hline
\end{tabular}

5 Style with apex slim (Fig. 5T) $\quad$ A. symmetrica Cao \& Zhang

- $\quad$ Style with apex triangular (Fig. 5U)

A. triangulata Cao \& Zhang

6

Pre-atrial process almost rectangular in ventral view, apex broad (Fig. 50)

A. quadrata Cao \& Zhang

- $\quad$ Pre-atrial process narrowing apically, apex pointed 7

$7 \quad$ Style with subapical tooth equal in length to apical tooth (Fig. 5A)

A. adaucta Cao \& Zhang

Style with subapical tooth shorter than apical tooth (Fig. 5P)

A. sphenoides Yang \& Zhang

8 Aedeagal shaft with pair of apical processes 9

- Aedeagal shaft without any apical process

A. confluensa sp. nov

9

Aedeagal apical processes arched medially in ventral view (Fig. 5B)

A. arcuata Yang \& Zhang

- Aedeagal apical processes slightly curved in ventral view

10

10 Aedeagal shaft with base slim, slightly wider than apex (Fig. 5X)

A. zelta Dworakowska

- $\quad$ Aedeagal shaft with base broad, much wider than apex 


\begin{tabular}{|c|c|c|}
\hline 11 & Aedeagal shaft constricted sub-basally (Fig. 5J) & A. jinghongensis Cao \& Zhang \\
\hline- & Aedeagal shaft not constricted sub-basally & 12 \\
\hline 12 & $\begin{array}{l}\text { Style with apical tooth extremely small, aedeagal shaft } \\
\text { straight (Fig. } 5 R \text { ) }\end{array}$ & A. subdentata Yang \& Zhang \\
\hline- & $\begin{array}{l}\text { Style with apical tooth relatively long, aedeagal shaft } \\
\text { curved dorsad }\end{array}$ & A. ciconia Dworakowska \\
\hline 13 & Aedeagal shaft with processes near middle (Fig. 5V) & A. triprocessa Yang \& Zhang \\
\hline- & Aedeagal shaft without process near middle & 14 \\
\hline 14 & Apex of style serrated at middle & 15 \\
\hline- & Apex of style smooth at middle & 18 \\
\hline 15 & $\begin{array}{l}\text { Upper tooth of pygofer dorsal appendage much shorter } \\
\text { than lower one (Fig. 5D) }\end{array}$ & $\begin{array}{l}\text { A. bauhinicola Dworakowska \& } \\
\text { Viraktamath }\end{array}$ \\
\hline- & $\begin{array}{l}\text { Upper tooth of pygofer dorsal appendage subequal to or } \\
\text { longer than lower one }\end{array}$ & 16 \\
\hline 16 & $\begin{array}{l}\text { Upper tooth of pygofer dorsal appendage longer than } \\
\text { lower one (Fig. 5F) }\end{array}$ & A. expansa Cao \& Zhang \\
\hline- & $\begin{array}{l}\text { Upper tooth of pygofer dorsal appendage almost as long } \\
\text { as lower one }\end{array}$ & 17 \\
\hline 17 & $\begin{array}{l}\text { Apex of pre-atrial process rounded, with one side } \\
\text { serrated (Fig. } 5 \mathrm{M})\end{array}$ & A. plana Yang \& Zhang \\
\hline- & $\begin{array}{l}\text { Apex of pre-atrial process truncate, with both sides } \\
\text { smooth (Fig. } 5 \mathrm{E} \text { ) }\end{array}$ & A. curva Yang \& Zhang \\
\hline 18 & $\begin{array}{l}\text { Ventral margin of aedeagal shaft protruded subapically in } \\
\text { lateral view }\end{array}$ & 19 \\
\hline- & $\begin{array}{l}\text { Ventral margin of aedeagal shaft straight subapically, in } \\
\text { lateral view }\end{array}$ & 21 \\
\hline 19 & $\begin{array}{l}\text { Apical tooth of style almost equal to subapical tooth (Fig. } \\
5 \mathrm{~K})\end{array}$ & A. liubanus Yang \& Zhang \\
\hline- & Apical tooth of style greatly shorter than subapical tooth & 20 \\
\hline 20 & $\begin{array}{l}\text { Aedeagal shaft processes relatively long, gonopore } \\
\text { central (Fig. } 5 \mathrm{~L} \text { ) }\end{array}$ & A. parisakazu Cao \& Zhang \\
\hline
\end{tabular}




\begin{tabular}{|c|c|c|}
\hline- & $\begin{array}{l}\text { Aedeagal shaft processes relatively short, gonopore } \\
\text { subapical }\end{array}$ & A. akazu Matsumura \\
\hline 21 & Apex of pre-atrial process serrated laterally (Fig. 5I) & A. fusina Yang \& Zhang \\
\hline- & Apex of pre-atrial process smooth & 22 \\
\hline 22 & $\begin{array}{l}\text { Pre-atrial process rudimentary, as long as } 1 / 5 \text { of } \\
\text { aedeagal shaft (Fig. } 5 \mathrm{C})\end{array}$ & A. badjawae Dworakowska \\
\hline- & Pre-atrial process much longer than $1 / 5$ of aedeagal shaft & 23 \\
\hline 23 & Aedeagal shaft curved dorsad (Fig. 5G) & A. falcata Yang \& Zhang \\
\hline- & Aedeagal shaft straight & 24 \\
\hline 24 & Apex of style slender (Fig. $5 \mathrm{~N}$ ) & A. qinlingensis Yang \& Zhang \\
\hline- & Apex of style foot-like & 25 \\
\hline 25 & Aedeagal shaft with processes arising from subapex & 26 \\
\hline- & Aedeagal shaft with processes arising from apex & 27 \\
\hline 26 & Apex of aedeagal shaft expanded (Fig. 5H) & A. forcipiformis Yang \& Zhang \\
\hline- & Apex of aedeagal shaft narrow (Fig. 5Q) & A. subapicifixa Yang \& Zhang \\
\hline 27 & $\begin{array}{l}\text { Aedeagal shaft processes bent at right angle in ventral } \\
\text { view }\end{array}$ & A. rolikae Dworakowska \\
\hline- & $\begin{array}{l}\text { Aedeagal shaft processes straight or slightly curved in } \\
\text { ventral view }\end{array}$ & 29 \\
\hline 28 & Style without distinct apical and subapical teeth (Fig. 5S) & A. sufflata Yang \& Zhang \\
\hline- & Style with distinct apical and subapical teeth & 29 \\
\hline 29 & Gonopore subapical (Fig. 5W) & A. wolongensis Yang \& Zhang \\
\hline- & Gonopore central & A. maculosa Dworakowska \\
\hline
\end{tabular}




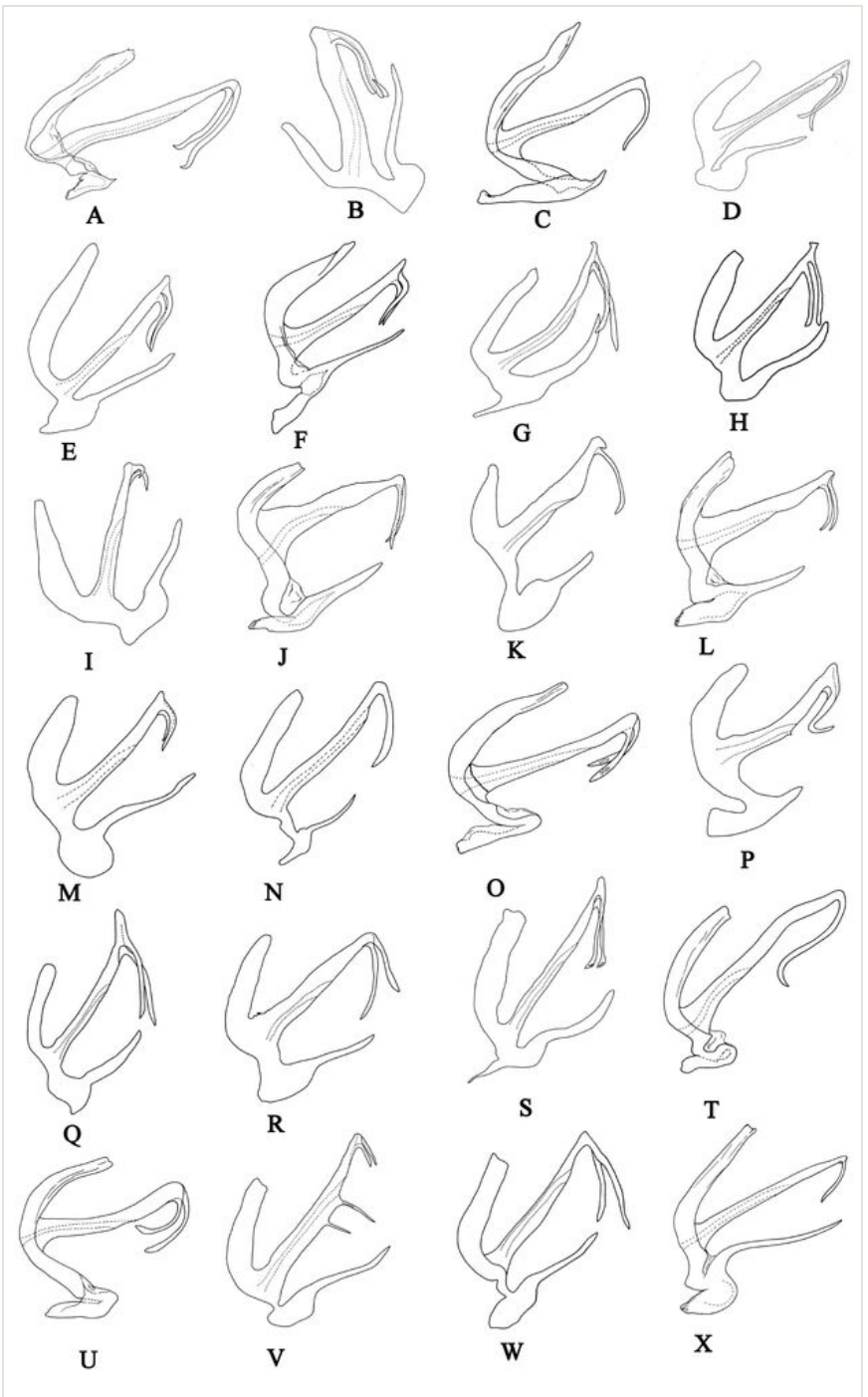

Figure 5. doi

Aedeagus of Anufrievia spp, lateral view. A. A. adaucta Cao \& Zhang, 2018; B. A. arcuata Yang \& Zhang, 2018; C. Anufrievia badjawae Dworakowska, 1976; D. Anufrievia bauhinicola Dworakowska \& Viraktamath, 1978; E. A. curva Yang \& Zhang, 2018; F. A. expansa Cao \& Zhang, 2018; G. A. falcata Yang \& Zhang, 2018; H. A. forcipiformis Yang \& Zhang, 2018; I. A. fusina Yang \& Zhang, 2018; J. A. jinghongensis Cao \& Zhang, 2018; K. A. liubanus Yang \& Zhang, 2018; L. A. parisakazu Cao \& Zhang, 2018; M. A. plana Yang \& Zhang, 2018; N. A. qinlingensis Yang \& Zhang, 2018; O. A. quadrata Cao \& Zhang, 2018; P. A. sphenoides Yang \& Zhang, 2018; Q. A. subapicifixa Yang \& Zhang, 2018; R. A. subdentata Yang \& Zhang, 2018; S. A. sufflata Yang \& Zhang, 2018; T. A. symmetrica Cao \& Zhang, 2018; U. A. triangulata Cao \& Zhang, 2018; V. A. triprocessa Yang \& Zhang, 2018; W. A. wolongensis Yang \& Zhang, 2018; X. Anufrievia zelta Dworakowska, 1977. 


\section{Acknowledgements}

This study was partly funded by the World Top Discipline Program of Guizhou Province: Karst Ecoenvironment Sciences (No.125 2019 Qianjiao Keyan Fa), the Guizhou Provincial Science and Technology Foundation ([2018]1411), the Guizhou Science and Technology Support Project ([2019]2855), the Science and Technology Project of Guiyang City ([2020]7-18), the Innovation Group Project of Education Department of Guizhou Province ([2021]013), the Training Program for High-level Innovative Talents of Guizhou Province ([2016]4020) and the Project for Regional Top Discipline Construction of Guizhou Province: Ecology in Guiyang University [Qian Jiao Keyan Fa [2017]85].

\section{References}

- $\quad$ Cao YH, Yang MX, Lin SH, Zhang YL (2018) Review of the leafhopper genus Anufrievia Dworakowska (Hemiptera: Cicadellidae: Typhlocybinae: Erythroneurini). Zootaxa 4446 (2): 203-232. https://doi.org/10.11646/zootaxa.4446.2.2

- Dietrich CH (2005) Keys to the families of Cicadomorpha and subfamilies and tribes of Cicadellidae (Hemiptera: Auchenorrhyncha). Florida Entomologist 88: 502-517. https://doi.org/10.1653/0015-4040(2005)88[502:KTTFOC]2.0.CO;2

- Dworakowska I (1970) On the genera Asianidia Zachv. and Singapora Mahm. with the description of two new genera (Auchenorrhyncha, Cicadellidae, Typhlocybinae). Bulletin de l'Academie Polonaise des Sciences 18 (12): 759-765.

- Dworakowska I (1993) Remarks on Alebra Fieb. and Eastern Hemisphere Alerini (Auchenorrhyncha: Cicadellidae: Typhlocybinae). Entomotaxonomia 15 (2): 91-121.

- Matsumura S (1932) A revision of the Palaearctic and Oriental typhlocybid-genera with descriptions of new species and new genera. Insecta Matsumurana 6 (3): 93-120. 